\section{A gênese da disciplina gramatical: a influência da escrita*}

The genesis of grammatical discipline: the influence of writing

Emanuela Monteiro GONDIM (UFC) emanuelamonteirogondim@gmail.com

Recebido em: 11 de abr. de 2019. Aceito em: 03 de out. de 2019.

* Este trabalho foi desenvolvido a partir de uma comunicação oral apresentada na XXIV Semana de Estudos Clássicos sob a orientação do Prof. Paulo Mosânio Teixeira Duarte, por quem terei sempre profunda admiração e imenso carinho. Fonte inesgotável de conhecimento, ele foi essencial para a minha formação e a de tantos outros que tiveram a sorte de conviver com ele.
GONDIM, Emanuela Monteiro. A gênese da disciplina gramatical: a influência da escrita. Entrepalavras, Fortaleza, v. 10, n. esp., p. 65-74, ago. 2020. DOI: 10.22168/2237-63218 esp1717.

Resumo: Este trabalho tem como objetivo mostrar como a escrita foi mais valorizada que a oralidade durante a criação da disciplina gramatical, tékhne grammatike, à época helenística, e mostrar ainda como essa visão hierarquizante dessas duas modalidades da língua ainda está presente atualmente. Enquanto, no período helênico, os estudiosos gregos voltavam-se para a criação do pensamento grego, no período helenístico, a preocupação dos estudiosos era preservar as criações do período helênico. Desse modo, dedicaram-se ao estudo das obras literárias de autores essencialmente gregos, principalmente Homero, para estabelecer o padrão da autêntica língua grega e protegê-la das corrupções bárbaras, oriundas do contato com diversas culturas estrangeiras. Dessa forma, é notável que a gramática tradicional ocidental é notável que a gramática tradicional ocidental tenha sido ainda um eco daquela gramática helênica inicial, através da ars grammatica dos gramáticos latinos.

Palavras-chave: Escrita. Gramática tradicional. Período helenístico. 
v. 10 (esp.)

65-74 ago. 2020

Abstract: This paper aims at showing how the writing was more valued than the oral speech during the creation of grammatical discipline, grammatike tékhne, in the hellenic period, and how this hierarchical relationship between these two aspects of language is still present in our modernity so far. While, in the first moment, the greek scholars were focused on the creation of greek thought, they were, in the next one, interested in preserving the literary patterns of the hellenic period. Thus, they dedicated their attention only to literary works by authors Greeks, especially Homer, in order to establish the pattern of the authentic greek language and to prevent it from barbaric corruptions, originated from the contact with several foreign cultures. As a conclusion, it is remarkable that the traditional western grammar has still been an echo of that early hellenic grammar, through the ars grammatica by the latin grammarians.

Keywords: Writing. Traditional grammar. Hellenistic.

\section{Introdução}

A gramática ocidental, embrionária nos estudos filosóficos dos sofistas, de Platão e de Aristóteles, com o fim de resolver o problema das partes do discurso, chegou ao estatuto mais autônomo com Dionísio da Trácia, já bem semelhante à que vigorou no Ocidente. Floresceu na Grécia Antiga baseada no padrão escrito, em especial na literatura de grandes autores. Surgiu como resposta à necessidade de normativizar a língua grega que se tinha tornado o idioma oficial do grande império formado pelas conquistas de Alexandre no séc. IV a.C.. Noutras palavras, a gramática nasceu com o objetivo explícito de criar um padrão uniforme e homogêneo da língua grega que sobrepujasse as diferenças regionais e sociais para se transformar num instrumento de unificação política e cultural.

Desse modo, o que pretendemos, com este trabalho, é mostrar como a escrita foi mais valorizada que a oralidade durante a criação da disciplina gramatical, tékhne grammatike, à época helenística, e mostrar ainda como a visão hierarquizante dessas duas modalidades da língua ainda está presente atualmente. Para tanto, trataremos inicialmente das modalidades oral e escrita nas civilizações antigas. Posteriormente, discorreremos sobre os principais objetivos dos pensadores gregos nos períodos helênico e helenístico e sobre a importância da disciplina gramatical para o período helenístico.

\section{A oralidade e a escrita nas civilizações antigas}

Para entendermos a importância que a escrita assumiu na sociedade ocidental, cumpre retrocedermos na história para as primeiras civilizações inclinadas para a oralidade. Nessas culturas, assumem 
especial importância os narradores, já que podiam modificar a qualquer momento a história, acrescentando-lhe novos episódios ou adaptando-a simplesmente aos ouvintes. Era, portanto, pela palavra falada que os mitos passavam de geração a geração. O único processo de conservação da palavra era a memória pessoal, extremamente desenvolvida, tal como a memória social, a tradição e o costume. Era a civilização do diz-se, do rumor, em que a palavra podia tudo. A autoridade era dos mais velhos, que guardavam o tesouro das experiências ancestrais. Essa civilização oral produziu uma cultura difusa, uma literatura anônima, em que as obras não assinadas pertencem a todos e a ninguém.

Na sociedade grega, entre os séculos XII e VIII a.C., ainda uma civilização puramente oral, a memória era tida em grande conta. Indício disso era o lugar especial que ocupava a deusa Memória, Mnēmosýnē, no Panteão. Segundo Vernant (1973), "a sacralização de Mnēmosýnē marca o preço que lhe é dado em uma civilização de tradição puramente oral como o foi a civilização grega".

Para facilitar a memorização, grande parte dos mitos foram primitivamente veiculados sob a forma de poemas. Por volta do séc. IX a.C., surgiram duas importantes narrativas em verso: Ilíada e Odisséia, atribuídas ao poeta Homero. Elas representavam, para os gregos, não só o símbolo da sua unidade cultural enquanto povo, mas igualmente a expressão da sua religião, da sua visão do cosmos. As suas personagens eram verdadeiros modelos de comportamento que se seguia ou se evitava. Tais obras foram as primeiras que nos chegaram escritas do período arcaico, mas em uma escrita ainda fonética, já que foram compostas originalmente para serem ouvidas e não lidas.

Nas civilizações que cultivavam a oralidade, os poetas gozavam de grande prestígio. Eram olhados, conforme se observa no Íon de Platão, como instrumentos de um poder que os dominava e que falava através deles com a própria voz. Eram considerados profetas, visionários, homens que falavam várias línguas, agentes de forças invisíveis e desconhecidas. Daí o nome de vatis,- is, palavra associada a dons sobre-humanos, da qual veio "vaticínio", "profecia". A seguinte fala de Sócrates no Íon nos mostra claramente essa visão do poeta como um instrumento divino:

Pois essa pedra [a pedra que Eurípides chamou de "magnética"] não só atrai os próprios elos de ferro, mas ainda põe capacidade nos elos, para que por sua vez possam fazer o mesmo que a pedra faz - atrair outros anéis -, a ponto de às vezes uma cadeia muito extensa de anéis de ferros e elos ficar articulada 
v. 10 (esp.)

$65-74$ ago.

2020
[...]. Assim também a Musa faz por si mesma seus inspirados, e através desses inspirados - outros se inspirando - uma cadeia se articula. Pois todos os poetas dos versos épicos - os bons -, não por $a^{1} e^{1}$, mas estando inspirados e tomados, falam todos esses belos poemas, [...] é certo que os poetas nos dizem que é colhendo nas fontes de mel de certos jardins e vales das Musas que nos trazem as melodias - tal qual as abelhas, também eles próprios dessa maneira voando. E estão dizendo a verdade: porque poeta é coisa leve, e alada, e sagrada, e não pode poetar até que se torne inspirado ou fora de si, e a razão não esteja mais presente nele. Até conquistar tal coisa todo homem é incapaz de poetar e proferir oráculos. (PLATÃO, 2011, p. 32-33)

A escrita não gozava, em seu nascimento, de tanto prestígio entre os gregos. Na verdade, foi recebida com certo preconceito pelos guardiões da tradição oral. Apesar disso, os gregos, baseados no alfabeto fenício, constituem um alfabeto de melhor funcionamento que este devido à elaboração de sinais que designavam as vogais. Isso foi de grande utilidade na economia de sinais e eliminou a ambiguidade que havia na escrita que designava apenas as consoantes. Devido a essa simplificação, esse tipo de escrita se mostrou bem mais acessível que o modelo linear $b$ do período pré-homérico, que se caracterizava pela representação das sílabas. Ainda assim, o processo de disseminação da escrita foi bastante demorado e por um longo período os registros continuaram sendo passados oralmente, já que a escrita ainda não era conhecida por grande parte da sociedade. Dessa forma, percebemos que a oralidade grega passou por um longo período de resistência à escrita desde a criação do alfabeto, por isso, mesmo o alfabeto grego tendo se desenvolvido consideravelmente no que tange à representação fonética na língua grega (CAGLIARI, 2009), no início da transição da oralidade para a escrita, foi preciso registrar a oralidade antes de substituí-la. Assim a linguagem escrita vai se concretizando de forma lenta, após longo empenho em registrar por escrito obras originalmente orais.

Todavia, quando a escrita desenvolve melhor suas próprias características e passa a ser dominada por uma parte considerável da população, o que ocorreu, segundo os historiadores, por volta do século V a.C., a importância da poesia vai aos poucos se modificando e se ligando mais ao entretenimento, pois, com a atividade da escrita, a necessidade de memorização já não era tão intensa. Havelock (1996) acredita, inclusive, que a atividade da escrita é fundamental para o desenvolvimento dos estudos filosóficos, tendo em vista que, com o advento de um recurso mais eficiente para o acúmulo do saber, eles

\footnotetext{
${ }^{1}$ Nesse caso "Arte", em grego tékhne, pode significar técnica, habilidade ou profissão.
} 
tinham muito mais tempo para o desenvolvimento das ideias. A Filosofia de Platão e a de Aristóteles demonstram cabalmente o papel da escrita como mantenedora do já dito. Sem ela, não haveria quiçá o discurso controverso de Sócrates, que, não tendo sido escrito, não nos é conhecido plenamente.

\section{Os períodos helênico e helenístico}

É importante ressaltarmos que o período ao qual nos referimos até agora foi o helênico, época da hegemonia cultural ateniense, do apogeu da cultura grega. Todavia, o período que se mostra mais importante para o nosso trabalho é o que o sucede: o helenístico, momento em que a Grécia está enfraquecida por diversas guerras internas e externas, como, por exemplo, a Guerra do Peloponeso, que culminou na derrota de Atenas e, consequentemente, no fim das cidades-estados. Alexandre da Macedônia se aproveita dessa fraqueza para tomar a Grécia, que, desse modo, fica sob o domínio macedônico desde o século IV até o II a.C..

Por conta principalmente da nova organização política e social da Grécia, a saber, o fim das cidades-estados, ocorre um maior contato da língua e cultura grega com as dos povos bárbaros. Todas essas mudanças políticas e sociais fazem com que os estudiosos gregos tenham objetivos diferentes do que tinham no período helênico. Na época helenística, a grande preocupação já não era a criação, mas sim a preservação do que já havia sido criado no apogeu da cultura grega. Na verdade, a nova preocupação era não só a preservação, mas também a transmissão de tudo aquilo que havia sido criado na época helênica, a fim de proteger a cultura grega da corrupção que ela estaria sofrendo devido ao contato com os povos bárbaros. Assim, podemos dizer que, na época helenística, os estudiosos estavam voltados, principalmente, para as atividades de pesquisa e docência. Essa atividade docente era, segundo Neves (2005), sobretudo a transmissão de um patrimônio literário. É importante observarmos que a proteção da cultura estava intimamente ligada à proteção da língua. Sendo assim, buscava-se pesquisar e estudar as obras dos autores essencialmente gregos, ou seja, os que não tivessem a linguagem corrompida pelos barbarismos.

Cumpre ressaltar aqui os estudos da filologia e da crítica literária do período helenístico. Segundo Neves (2005), nesse período, a filologia tem um caráter distinto do que o que tinha na tradição grega - amor ao lógos, à palavra. Na época helenística, seu desiderato não era 


\section{v. 10 (esp.}

$65-74$ ago. 2020

apenas resgatar os textos literários de valor, mas também explicar os sentidos de palavras os quais se perderam ao longo do tempo. Convinha ao filólogo o estudo dos autores de expressão bela e correta.

Ao lado da filologia, desenvolve-se também uma crítica literária, feita pelo gramático, em grego grammatikós, que, além de explicar as obras, tem o poder de julgá-las (tanto em relação a sua qualidade, quanto a sua autenticidade). As pesquisas do gramático também estavam ligadas à docência, já que ele era o mestre-escola que sucedia ao gramatista (em grego, grammatistés, o instrutor que alfabetizava as crianças), e seus tratados de gramática eram publicados a fim de auxiliar a leitura dos primeiros poetas gregos. De tal forma, tanto a filologia, quanto a crítica literária, com o intento de fixar a língua literária e a escrita, voltam-se para um estudo que irá resultar na gramática.

\section{O nascimento da gramática}

Conforme Neves (2005), a gramática surge como parte do estudo literário, característico do período helenístico, mas há, no processo de sua instituição, um fundo filosófico, já que foi influenciada pelos estudos das escolas de Pérgamo, que se fundavam nos estudos estóico-filosóficos da língua, e de Alexandria, que eram influenciados por Aristóteles.

Os estoicos, em seus trabalhos etimológicos, partiam das onomatopeias para explicar a relação entre a palavra e o objeto, considerando que essa relação não estava ligada a uma subjetividade arbitrária, pois acreditavam que "foi a natureza humana que fez sair da garganta o ar impulsionado por cada afecção ou cada percepção, de modo diferente em cada povo e em cada lugar" (NEves, 1987, p. 97). Entretanto, ao encontrarem casos de discordância entre o som e o conceito de algumas palavras, eles perceberam que nem sempre essa relação palavra/objeto é motivada. Dessa forma, os estoicos passam a admitir e pesquisar as anomalias da linguagem, por exemplo, palavras chamadas masculinas, mas que, na verdade, são masculinas apenas quanto à forma, mas não quanto ao significado; palavras de significado negativo, mas que podiam ser usadas como positivas. Desse modo, os estudiosos da escola de Pérgamo, que, como já mencionamos anteriormente, eram influenciados pelos estoicos, estudavam e pesquisavam os fenômenos da anomalia, dando proeminência às irregularidades linguísticas. Consideravam os textos literários, na tentativa de explicar os textos homéricos. 
Os estudiosos alexandrinos, por seu turno, influenciados por Aristóteles, usavam o princípio da anomalia simplesmente para o expurgo das formas tidas como erradas, consideravam que as anomalias não faziam parte do padrão da língua grega, o que as colocava como inferiores. Seu estudo era fundado na analogia, que salientava as regularidades da língua. Voltavam-se aos textos literários escritos com o objetivo de editá-los, purificando-os de tudo o que julgavam espúrio. Excluíam não só o barbarismo (a linguagem não-grega), como também o dialeto (a linguagem grega que não constitui padrão constante). Com os gramáticos alexandrinos, as considerações sobre a linguagem saem do terreno filosófico para o campo propriamente gramatical. Nasce, portanto, a gramática como exposição dos fatos da língua helênica, que constitui, segundo Neves, a consolidação da analogia linguística.

Édenotar-se,nessaconjuntura, a escritacomohierarquicamente superior à fala, pois ela teria registrado a língua dos tempos áureos da sociedade grega. Tal supremacia é refletida, inclusive, pelo substantivo

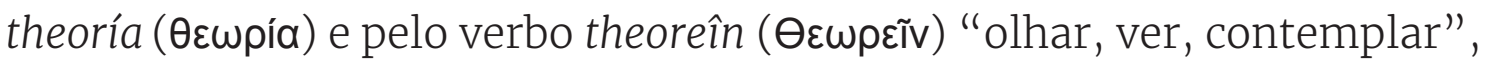
usados por Aristóteles, para referir-se à atividade especulativa a que se dedicavam as pessoas no Lyceum. Ambos descrevem uma atividade intelectual se referindo ao ato de ver, de observar algo e não de ouvir algo, ou seja, a atividade intelectual já se mostra intimamente ligada à possibilidade de ver a palavra escrita e não apenas de ouvi-la, como era próprio das civilizações orais.

A propósito, a transição de uma sociedade oral para uma sociedade letrada teve o efeito de uma revolução cultural que levou a uma espécie de endeusamento da escrita no período helenístico. Prova disso é a formação das já mencionadas disciplinas de filologia e crítica literária, que se empenhavam no resgate e na análise de textos literários escritos. Se os poetas gregos eram vistos, na tradição oral, como porta-vozes das Musas, filhas da Memória, a escrita representa, na época helenística, a libertação, como se qualquer cidadão letrado se tornasse também um porta-voz. O domínio da escrita passa a se identificar também com o poder e a língua em sua totalidade passa a se confundir com a língua escrita, tanto é que os estudiosos da linguagem, filólogos e críticos, voltavam-se apenas para o escrito, como bem assinala Havelock (1996):

Desde entonces, se podía pensar todo lenguaje como lenguaje escrito. Se llegó a considerar el texto leído como equivalente de la palabra hablada. Dado que los eruditos y especialistas trabajan casi exclusivamente con textos, se ha formado la suposición de que La escritura es idéntica al lenguaje o, de 
v. 10 (esp.)

65-74

ago.

2020

hecho, que la escritura es lenguaje y no sólo un «artefacto» visual que sirve para desencadenar, por asociación simbólica, el recuerdo de una serie de ruídos lingüísticos (HAVELOCK, 1996, p.150-151) ${ }^{2}$.

A língua tida como verdadeiramente grega estaria registrada, no nascedouro da gramática, nos documentos literários escritos e não na fala corrente, que, evoluindo mais rapidamente que a escrita, teria se deixado corromper com mais facilidade. É de bom alvitre salientar o que pode ser visto inclusive no significado do termo grego, gramatiché үраннатıкń, "arte de ler e escrever". Tal definição deixa bem clara a importância da escrita na formação gramatical, uma vez que existe a supremacia da escrita diante da oralidade, pois esta aparece nessa definição apenas como leitura, isto é, como subserviente à escrita. Esta noção está presente em gramáticas posteriores, como na de João de Barros, do século XVI, reproduzida abaixo.

Grammatica, e uocabulo Grægo: quer dizer, çiençia de leteras. E segundo a difinçám que lhe os Grãmáticos dęrã:ç hũ módo certo e iusto de falar, e escrever, colheito do uso, e autoridade dos barões doutos. Nós podemos lhe chamar artefiçio de paláuras, postas ẽ seus naturáes lugares:pera que mediãte ellas, assy na fala como na escritura, uenhamos em conhiçimento das tenções alheas. Por que bem assy emtram as leteras pela uista, como nosso intendimẽto reçebe as mais das cousas (BARROS, 1540, n.p.) $)^{3}$.

Podemos dizer que esta noção de gramática se acha subjacente nas obras modernas que continuam pautando seus modelos na língua escrita. A título de ilustração, tomemos os seguintes excertos de gramáticas atuais.

Com esse propósito, procuramos abonar os fatos lingüísticos quase que exclusivamente com citações de autores contemporâneos [...]. Evitamos, com o máximo de cuidado, o

\footnotetext{
${ }^{2}$ Desde então, podia-se pensar toda a linguagem como linguagem escrita. Passou-se a considerar o texto lido como equivalente à palavra falada. Dado que os eruditos e os especialistas trabalhavam quase exclusivamente com textos, formou-se o pressuposto de que a linguagem escrita era idêntica à linguagem oral, ou seja, de que a escrita é linguagem e não só um «artefato» visual que serve para desencadear, por associação simbólica, a memória de uma série de ruídos linguísticos. (HAVELOCK, 1996, p. ) [tradução nossa]

3 Gramática é vocábulo grego, quer dizer a ciência das letras. E, segundo a definição que lhe deram os gramáticos, são um modo certo e justo de falar e escrever, colhido do uso da autoridade dos barões doutos. Nós podemos lhe chamar artifício de palavras postas em seus lugares naturais. Mas que mediante elas, tanto na fala como na escrita, venhamos a conhecer as intenções alheias. Porque do mesmo modo que entram as letras pela vista, nosso entendimento recebe as mais das cousas. [adaptação nossa] (BARROS, 1540, n.p.).
} 
dogmatismo intransigente e impositivo e as soluções pessoais e arbitrárias, fundamentando sempre a doutrinação no uso vivo do idioma e na lição dos bons escritores. [...]. (CEGALLA, 1993, p.14).

Fundamentam-se as regras da gramática normativa nas obras dos grandes escritores, em cuja linguagem as classes ilustradas põem o seu ideal de perfeição, porque nela é que espelha o que o uso idiomático estabilizou e consagrou (Rocha Lima, 1992, p.7). [grifos nossos]

Nota-se que o modelo a ser seguido continua sendo a escrita literária de grandes autores, se não a dos gregos, a do que os gramáticos modernos denominam "bons autores" da língua portuguesa. Esta concepção dá margem a sérios equívocos na abordagem do tema, com efeitos deletérios sobre o ensino, entre os quais, destacamos:

a) A insistência em modelar a gramática pela lição de escritores, sem considerar os usos linguísticos de gêneros não-literários;

b) A desconsideração da variação diatópica, diafásica e diastrática, apresentando modelos anacrônicos e descontextualizados;

c) A rigidez da oposição certo x errado, sem consideração dos contextos sociais em que determinados usos se aplicam;

d) A associação de língua inculta e informal com língua falada, como se a língua falada, tal como a escrita, não se submetesse a registros;

e) A desconsideração de qualquer ensinamento formal dos empregos da língua falada, como se apenas a escrita precisasse ser aprendida na escola.

Não se nega o valor e o poder da escrita, especialmente, em uma sociedade letrada como a nossa. Reconhece-se ademais seus efeitos sobre o pensamento e a cultura ocidental, de que somos herdeiros. Todavia, confundi-la com a própria língua, como o faz a gramática normativa, é esfacelar um fenômeno por si só múltiplo e complexo.

\section{Considerações finais}

Diante do exposto, fica evidente que a escrita, embora tenha demorado a se consolidar na cultura grega, teve grande influência na formação da disciplina gramatical durante a época helenística. Tal 
V. 10 (esp.)

65-74

ago.

2020

disciplina é fruto dos estudos da filologia, ciência de preservação da escrita e de resgate do texto, e da crítica literária, ciência que tinha o poder de julgar tanto a autenticidade, quanto a qualidade dos textos, e seu nascimento ocorre em um momento histórico-social de decadência no qual se fazia importante para os gregos a preservação de seu glorioso passado. Nessa conjuntura, a gramática acaba se confundindo com a própria língua, ou melhor, com a língua pura, por isso se julga que conhecer uma língua é dominar sua gramática, ou melhor, suas regras gramaticais.

\section{Referências}

BARROS, J. de. Grammatica da língua portuguesa. Olyssipone: apud LodouicumRotorigiu[m], Typographum, 1540. Disponível em: <http://purl. pt/12148> Acesso em: 28 out. 2011.

CAGLIARI, Luiz Carlos. A História do Alfabeto. São Paulo: Paulistana, 2009.

CEGALLA, D.P. Novíssima gramática da língua portuguesa. São Paulo: Editora Nacional, 1993.

HAVELOCK, E.A. La musa aprende a escribir: reflexiones sobre oralidad y escritura desde la Antigüedad hasta el presente. Barcelona: Paidós, 1996.

NEVES, M.H.M. A vertente grega da gramática tradicional: uma visão do pensamento grego sobre a linguagem. São Paulo: Editora UNESP, 2005.

PLATÃO, Íon. Tradução de Cláudio Oliveira. Autêntica Editora: Belo Horizonte, 2011.

ROCHA LIMA, C.H. Gramática normativa da língua portuguesa. Rio de Janeiro: José Olympio, 1992.

VERNANT, J.-P. Mito e pensamento entre os gregos. Rio de Janeiro: Paz e Terra, 1990. 